\title{
Introduction: business and labour in climate policy
}

\section{BACKGROUND}

This book investigates the role of employers' organizations and trade unions in the development of climate change policy. It discusses the role of civil society actors including employers' organizations and trade unions in the policy development process, explores whether labour market considerations should be an element of climate change policy and applies ecological modernization and institutional governance theory to guide the consideration of these issues. Exploring the relationship between these practices, climate change policy and the labour market provides insights into the requirements of all stakeholders and informs the public policy process.

The authors are motivated by the belief that there is a need to inform policymakers on the labour market impacts and, equally, labour market practitioners of the impact that climate change policy will have on their sphere of interest. The objective of climate change policy is to reduce greenhouse gas (GHG) emissions, which requires change to patterns of production and consumption that has direct implications for the labour market. Public policy must take into account the labour market impacts of climate change or it may result in labour and skill shortages and displacement; these are issues that create barriers to the efficient conduct of business and the effectiveness of climate change mitigation and adaptation programmes. These issues can be avoided with proper planning.

The link between climate change and the labour market was formally recognized when the Heads of State and Government adopted the recommendations of the United Nations Framework Convention on Climate Change (UNFCCC) Adaptation Working Group (AWG) that climate change agreements provide for a just transition and decent work (UNFCCC AWG LCA, 2009). A just transition is defined as the recognition of workers' rights, decent work, social protection and social dialogue (Worldwatch Institute, 2008). The four tenets of decent work as articulated by the International Labour Organization (ILO) are creating good 
jobs, guaranteeing respect for workers and the recognition of their rights, extending social protection and promoting social dialogue (ILO, 2011a).

Government policies aimed at managing GHG emissions will require business to change its product and service delivery arrangements, which in turn means labour requirements will also change. With the increasing incidence of events attributed to climate change accelerating the timeframes and the radical changes required to address climate change, intervention in the labour market is necessary if labour is to be available in the numbers and with the skills required and if workers are to be afforded a just transition with rights and benefits as they transition to the new low carbon workplace.

While current international climate change commitments provide for the protection of workers' rights through the requirements for decent work and a just transition, they fall short of addressing the requirement for labour market reform. For labour market practitioners, this is deemed poor planning at best as disruption in the labour market is a certainty and, without addressing this requirement for reform, the chances of achieving ecological targets are diminished.

As a key actor in the regulation of labour markets and the development and enforcement of climate change policy, the state must also be considered in this discussion. Additional pressures on the state arising from the aftershocks of the global financial crisis, the discovery of new stocks of fossil fuels easing concerns about energy security and the growing ambition gap in international climate agreements are constant tests of the validity of the theoretical models that influence decision-making and public policy. The institutions involved with and responsible for policy development are being required to act quickly, yet the policy processes in which they are caught up often take years, if not decades, to negotiate outcomes acceptable to all parties.

The emergence of labour issues in formal climate agreements reflected the growing acceptance that climate change has impacts across the broader economy and society, and research published in 2007 and 2008 was instrumental in creating awareness of the employment and workplace impacts of climate change policy.

The Worldwatch Institute's (2008) report for the ILO encapsulates the findings that are common across research on the subject: due to the impact of climate change on public policy and the economy, there will be a consequential impact on the labour market and some jobs will be lost, some jobs will be created and some jobs will change. On balance, there will be a modest net growth in employment and all sectors of industry will be affected. It is contended by the ILO that governments must have policy to manage these changes and that social protection systems need 
to be in place to afford workers a just transition. The 2012 research by the International Labour Organizations' (ILO) International Institute of Labour Studies (ILO, 2012), updating the Worldwatch Institute (2008) Report reiterates the earlier findings, adding that outcomes for employment and incomes are largely determined by the policy instruments and the institutions (that is, the governance systems) that implement them, rather than being an inherent part of a shift to a greener economy.

This book is written at a time of increasingly erratic and disastrous weather patterns attributed to climate change and increasing acceptance across society of the need for action. Attention is shifting to the nongovernment sector for inspiration and initiative to support the international agreements that have not generated actions sufficient to contain the growth in global warming. The collegiate nature of decision-making in the European Commission, which includes employers' organizations and trade unions through the European Economic and Social Committee and across business more generally, suggests the opportunity exists for these interests to make a contribution to the development of effective climate change policy and also accept a shared responsibility for the present state of affairs.

\section{INTERNATIONAL AGREEMENTS}

International agreements are a pervasive influence over domestic climate change policy, particularly in the wake the of 2015 Paris Conference of the Parties (COP) during which the Parties (the member states) agreed to adopt the Lima Paris Action Agenda and its four pillars of the legally binding agreement, voluntary emission reduction commitment, finance and the role for non-state actors (NSAs). The background to the international negotiations and agreements provides an important insight to the emergence of climate change as a concern to humanity, the commitment to tackle the problem and the process issues to which resolution must be found for the effective implementation of the agreements.

Following the 1972 UN Conference on the Human Environment, as concerns about global warming and the future of the environment escalated, in 1983 the UN General Assembly established the World Commission on Environment and Development (WCED) to propose long-term environmental strategies for achieving sustainable development. The Commission's report Our Common Future (WCED, 1987) strongly influenced the Heads of State and Government in the lead-up to the 1992 UN Conference on Environment and Development (UNCED). The Conference, which became known as the Earth Summit, produced 
the Agenda 21 Plans for Action (UNCED, 1992), a blueprint for action to achieve sustainable development worldwide. It also produced the Forest Principles, the Convention on Biological Diversity and the Framework Convention on Climate Change (UNCSD, 2012a). Within five years of the Earth Summit, the 1997 Conference of the Parties (COPs) to the UN Framework Convention on Climate Change (UNFCCC) had agreed to the Kyoto Protocol (KP), which embraced the agreement between developed and developing countries to work together to meet the climate change challenge and developed countries would commit to emission reduction targets (UNFCCC, 1997). The 2015 Paris Agreement succeeded the Kyoto Protocol and sees all countries commit to programmes of emissions reduction.

KP set targets on the ratifying signatories, who represented 37 industrialized countries and the European community, for reducing GHG emissions (UNFCCC, 1997). The Paris Agreement provided that ratifying countries act in accordance with their intended nationally determined contributions (INDCs). ${ }^{1}$ Almost all countries have declared their intension to ratify the Agreement. Even so, there is little consistency in the mitigation policy and programme development of the nation-states globally because the circumstances of each country are different and, as the OECD and others agree, there is no one solution that can be applied to all.

The European Union (EU) was an active participant in the 1992 Earth Summit and a signatory to the subsequently ratified 1997 the Kyoto Protocol. The 1993 Treaty of Maastricht added the protection of the environment to the EU objectives of economic growth and social wellbeing (Europa, 2012a). Prior to the ratification of the Treaty of Maastricht, many countries within the EU had already moved to reduce their GHG emissions and to address concerns about energy security and the development of alternatives to fossil fuels (Syndex, 2011). In doing this, the EU and member states provide a working model of ecological governance that is comprehensive, mature and respects the autonomy of the state in determining domestic policy while operating within a regional framework. The EU and member countries provide a model of sustainability management and public policy development and as such are a rich source of valid data for research.

The attention afforded the economic and social issues alongside the climate imperative and the perceived needs of civil society has impacted the efficiency of the international climate change agreement negotiating process and efforts to meet the global warming targets. The 2011 Durban COP was criticized for its weak outcomes and slow progress and was generating a concern among stakeholders that the negotiators would be able to reach agreement on a successor to the Kyoto Protocol, concerns that 
have now been mitigated to some extent by adoption of the 2015 Paris Agreement and the commitments to further action.

The agreements from the Rio +20 Conference (UNCSD, 2012a) and the UNFCCC COPs are major influences on the decisions of the state and the policy choices for climate change mitigation strategies. The agreements have as their objective sustainable development, which they describe as the delivery of environmental protection, economic growth and social wellbeing (UNCSD, 2012a; UNFCCC, 2011b). The Bali Action Plan (UNFCCC, 2007) prioritized the requirement that the economic and social consequences of adaptation to climate change be considered in negotiations. The Rio + 20 outcomes document The Future We Want (UNCSD, 2012a) contains these provisions as well as others addressing directly the issues of poverty eradication, the engagement of civil society, a green economy and institutional arrangements.

While comprehensive and well-intentioned, these requirements may have created a barrier to the effective implementation of the agreements. This is reflected in the growing concern among observers and interest groups that the climate agreements may not deliver on their target of containing the average increase in global temperature to less than 2 degrees, that civil society is becoming disenfranchised, that negotiators have so far failed to address the ambition gap and that there may be claims for compensation from developing countries and disputes over intellectual property rights (for example, Climate Action Network, 2012; Fisher, 2010; Eastwood, 2011). The outcomes from the 2015 Paris COP, while yet to be implemented, saw the Parties respond in a positive manner and provide hope that these concerns have been addressed.

The outcome agreements from the recent UN events including Rio +20 and the UNFCCC COPs have been lauded as either positive demonstrations of multilateralism or criticized as insufficient to address the environmental concerns (for example, WTO, 2012; Climate Action Network, 2012; BusinessEurope, 2012). Time-consuming and unresolved issues from the UNFCCC COPs at Durban and Doha included intellectual property rights, finance and claims by developing nations for disaster compensation, issues which can only be described as incidental to the environmental objective (BusinessEurope, 2012). The 2010 Cancun Agreement (UNFCCC, 2010) and Rio + 20 outcome agreement added commitments to labour reform. The merits or otherwise of these additions are not at issue: at issue is whether international environmental and climate fora are the appropriate places for them to be negotiated and whether they encumber the ability to negotiate agreements that could address the ambition gap. The 2012 Doha COP heard arguments by developed countries that other fora such as the World Trade Organization (WTO) and World Intellectual 
Property Organization (WIPO) would be better placed to resolve intellectual property issues (Climate Action Network, 2012). The same could be said of the ILO in respect to the emerging labour issues. It is noted that these issues have not been carried forward into the decisions from the Paris COP, which may bode well for efficiency of future COPs and the implementation strategies. A legally binding core agreement stripped of these and the other non-core issues that 'cluttered' the Cancun and later COPs may improve the efficiency of decision-making.

The Rio +20 outcome agreement included in its work programme an employment and workplace dimension by providing for the promotion of a just transition, decent work and social protection (UNCSD, 2012a). The UNFCCC climate change agreements had added a similar commitment at its 2010 Cancun COP (UNFCCC, 2010). The emergence of labour issues in formal sustainability and climate agreements reflects the growing acceptance that climate change has impacts across the broader economy and society.

The labour matters introduced into the Rio +20 agreement at Articles 147-157 are comprehensive and present a thorough checklist of rights and obligations. They are also under the authority of specialized international agencies and in many countries are already principles of national labour law and practice (ILO, 2011). The potential jurisdictional conflict is mitigated to an extent by use of terminology that has wide application and recognition in formal international and industrial texts. This could imply a UN intention to endorse existing law and practice rather than to create new benchmarks for performance, even though the Parties are testing their authority in other fora.

The Paris COP, held in December 2015, adopted the framework of the Lima Paris Action Agenda (LPAA) and its four pillars: the binding Paris Agreement, voluntary country contributions (INDCs), finance and an enhanced role for NSAs. The Paris Agreement introduces a management model to ensure transparency in the reporting of voluntary undertakings that will operate in concert with the binding Paris Agreement and a modified system for monitoring and evaluation (UNFCCC, 2015, paragraphs 85-104). These arrangements will be integral to the effectiveness of the LPAA and of relevance to the governance framework presented in this volume.

The negotiations in the period leading up to the 2015 Paris COP were tense and closely monitored. The UNFCCC regular mid-term meetings of the Parties to the Convention in June 2015 in Bonn was the penultimate negotiating session and, while the Parties expressed their commitment to a process publicly, this did not translate to progress on streamlining the negotiating text. The meeting was also coming to terms with the need to 
share responsibility with non-Party actors, a reflection of acceptance that the targets for global warming and GHG emission containment could not be achieved by the states acting alone. This is a material shift whereby the concepts of shared responsibility and shared decision-making were to be introduced into UNFCCC governance, a role beyond business as usual for Parties and the civil society organizations (CSOs).

The objective of the UNFCCC is to stabilize greenhouse gas concentrations at a level that would prevent dangerous anthropogenic (humaninduced) interference in the climate system (United Nations, 1992). The 2010 Cancun COP resolved to commit to action that would contain warming to a maximum temperature rise of 2 degrees Celsius above preindustrial levels and to consider lowering that maximum to 1.5 degrees in the near future (UNFCCC, 2010), a commitment reiterated at the 2015 Paris COP (UNFCCC, 2015). The IPCC 5th Assessment Report (IPCC, 2014), however, provides a sobering review, reporting that without additional efforts to reduce GHG emissions beyond those in place today, global emissions growth is expected to persist (Christ, 2014) putting the 2-degree target out of reach.

The negotiations for the agreement to succeed the Kyoto Protocol began in 2007 with the Bali Action Plan (UNFCCC, 2007), intended to be finalized for resolution at the 2009 Copenhagen COP. The Parties at Copenhagen did not adopt the negotiated text and subsequent COPs also failed to agree terms for the next generation treaty. The Parties, however, rose to the occasion of the deadline of the 2015 Paris COP delivered a strong outcome. Time will tell whether the outcome and the enthusiasm from the COP are sufficient to deliver the 2-degree global warming objective and to bridge the gap between the voluntary commitments of the INDCs and the emission reductions required.

In his address to the Plenary of the UNFCCC meetings of June 2015, the incoming COP President, Laurent Fabius, France's Foreign Minister, foreshadowed the intended structure of the outcomes from the twenty first COP and the eleventh Conference Meeting as Parties to the Protocol (CMP) (COP21/CMP 11) held in Paris 30 November-11 December 2015 (Fabius, 2015). The stated vision of the French government for Paris 'focuses on actions pre 2020, as well as afterwards' (p. 1). Its Action Agenda sought to trigger the growing engagement of NSAs and proposed dialogue during the COP with national governments, cities and businesses (UNFCCC LPAA, 2015), effectively harnessing the willingness of the major corporations to act (Cameron et al., 2015) and tap finance opportunities from the private sector (Business and Climate Summit, 2015). The dialogue was conducted as proposed and the announcements of their commitment and proposed actions post-COP by these non-Party stakeholders 
is testament to the vision and effectiveness of the strategy (Food and Beverage Leaders, 2015; Gillis and St. Fleur, 2015; Pianigiani, 2015).

Reaching out to the business community and others who, by their own actions can reduce GHG emissions and impact the effectiveness of adaptation and mitigation strategies, is a logical and mature rationale. It does, however, introduce other considerations, importantly the monitoring and evaluation process. It also has the effect of subordinating the preeminence of the agreement that will be binding on governments, being only one of the four pillars of action and then with the key role as a technical standardsetting authority for measurement and reporting. It can be said that the four-pillar model is a reflection of society's concerns for the issue and its resolve to act (and the inability of the state alone to deliver the targeted outcome), but this comes at the expense of the capacity to enforce binding limits and timeframes.

The 2015 Paris COP has formally adopted an agreement in two parts: the core agreement and decisions. The core agreement (the Paris Agreement) will be legally binding on all parties and will address the ambition, requirements for adaptation and mitigation, financing and implementation. The Decisions of the COP contain the detail that may be varied as required and appropriate. The further voluntary commitments by each Party to emission reduction will be through the INDC. The four pillars of the Action Agenda as described earlier are the legal agreement, ambitious INDCs, long-term finance and a commitment from NSAs. This is a model that could deliver strong and appropriate governance; however, the success of the model is contingent on bridging the outstanding gap between the aggregate of the INDCs and the emission reductions required for containing global warming to less than the 2-degree objective. The Decisions document is precise, clear and provides a detailed and thorough work plan for the Parties and the UNFCCC Secretariat. It does not make the promises of the previous agreements to do everything for everyone, such as the labour and trade issues already referred to above. The Agreement is more forgiving but is still focused on the climate issues.

The outcome from the 2015 Paris COP is widely agreed as a solid platform for managing the policy necessary to address the issues arising from climate change and to that end the Paris COP is described as the negotiating event and COP 22 in Morocco in November 2016 as deciding the implementation arrangements. The Paris COP and the attention it created around the problem of climate change has inspired a number of parallel initiatives by governments such as the Coalition of Carbon Pricing (made up of governments that are now implementing or are proposing emission trading schemes) and the Renewable Energy Initiative (made up of governments and other stakeholders). 
In respect to a global climate change initiative, it is a good outcome, and workable. For the business community, it is also a good outcome: it provides some certainty for decision-making; it does not presume to impose regulatory requirements over business and avoids issues relating to market behaviour and market mechanisms. It imposes obligations on the state for recording and reporting, but otherwise all issues relevant to business and possible regulation are contained in the governments' already submitted intended nationally determined contributions (INDCs).

In sum, the 2015 Paris COP agreed a framework for the management of climate change that is less centralized and relies more on the voluntary initiatives of the Parties individually, the private sector through the greening of their own activities and those in their supply chains, the financing of adaptation and mitigation and the broader network of NSAs. This is a bottom-up model which is different to the top-down model of Kyoto, and civil society resources need to be redirected accordingly, a change that may benefit many CSOs and allow many to play to their strengths in domestic policy. The converse may also be the case; CSOs may become less relevant as the UNFCCC creates an interface for direct dialogue with the broader community of NSAs.

\section{CASE STUDIES}

The book is built around a study of employers' organizations and trade unions, providing a unique set of perspectives of key stakeholding organizations. It draws from the experiences in eight countries (the United Kingdom (UK), France, Germany, Australia, Canada, Singapore, India and Kenya) and the European Union, with a detailed analysis of the European Union and the UK. The profiles were developed from a literature search of the governments, employers' organizations and trade unions in the countries selected. A survey was conducted across a broader community of trade unions and employers' organizations to gauge business and labour perceptions about their participation in climate-related policymaking. The results of the survey are used to inform the broader analysis of the book.

The European Union provides an established model of sustainability management and related public policy development and as such is a rich source of valid data for investigation. It is for this reason that the EU and member states with mature developed economies were selected for the case studies. The European Union (EU) was an active participant in the 1992 Earth Summit and a signatory to the subsequently ratified 1997 Kyoto Protocol. The 1993 Treaty of Maastricht added the protection of the 
environment to the EU objectives of economic growth and social wellbeing. Prior to the ratification of the Treaty of Maastricht and because of concerns about energy security, many countries within the EU had already moved to reduce their GHG emissions and to develop alternatives to fossil fuels. The pursuit of this objective has led to the creation of an ecological governance model that respects the autonomy of the state in determining domestic policy while operating within a regional framework.

\section{CENTRAL RESEARCH QUESTIONS AND MEANS OF ASSESSMENT}

The book asks the following questions:

1. Is the labour market significantly impacted by climate change policy?

2. Are employers' organizations and trade unions important actors in the development and implementation of climate change policy?

This book is informed by the theoretical framework of ecological modernization (EM), which contends that the relationship between the nationstate, the economy and innovation, and civil society are integral in the achievement of environmental outcomes - a theory that is increasingly used to guide public policy development. An important element in ecological modernization is civil society, which is often directly or by inference a reference to environmental activists. The book builds on and adds to existing theory by exploring the significance of labour market issues in climate change policy and the role of employers' organizations and trade unions as a further element and examining whether EM theory holds. As articulated by Mol et al. (2009), EM theorists agree that further research is required and that 'little is known still on how, to what extent and how successfully environmental interests are included in all kind of economic, cultural and political practices' (p. 511).

The intention of this book is to contribute to the body of knowledge that informs the theory of EM. It discusses the validity of the theoretical framework of EM and the gaps that exist between the theoretical framework and international and domestic policies, and how EM can and should be introduced into future policy development, monitoring and evaluation.

In view of the fact that EM theory is primarily directed towards understanding the interactions between the state, economy, ecology, and society, it is particularly relevant to studies of the governance of climate change management (Bailey et al., 2011). Developments in theory over the past couple of decades view the idea of governance as a means of coordinat- 
ing the processes and structures of governing that goes beyond traditional government/public administration models (Rhodes, 1997; Salomon, 2002). Governance, as opposed to government is now seen as a more relevant term for understanding the nature of non-state and state interactions in international policy, particularly when policymaking involves the market and society as well as the state (van Kersbergen and van Waarden, 2004; Kooiman, 2000), hence the strong conceptual linkages to EM theory.

In such a setting, institutions of policymaking are understood as placing more focus on structural and procedural aspects than models of governing based on command and control and a greater emphasis on the participation of stakeholders in decision-making (Pierre and Peters, 2000). In intergovernmental policy regimes such as the UNFCCC, the manner in which different actors behave towards each other determines how regimes are constructed and constituted and the subsequent quality of stakeholder interactions makes a significant contribution to governance effectiveness and institutional legitimacy overall (Figure I.1).

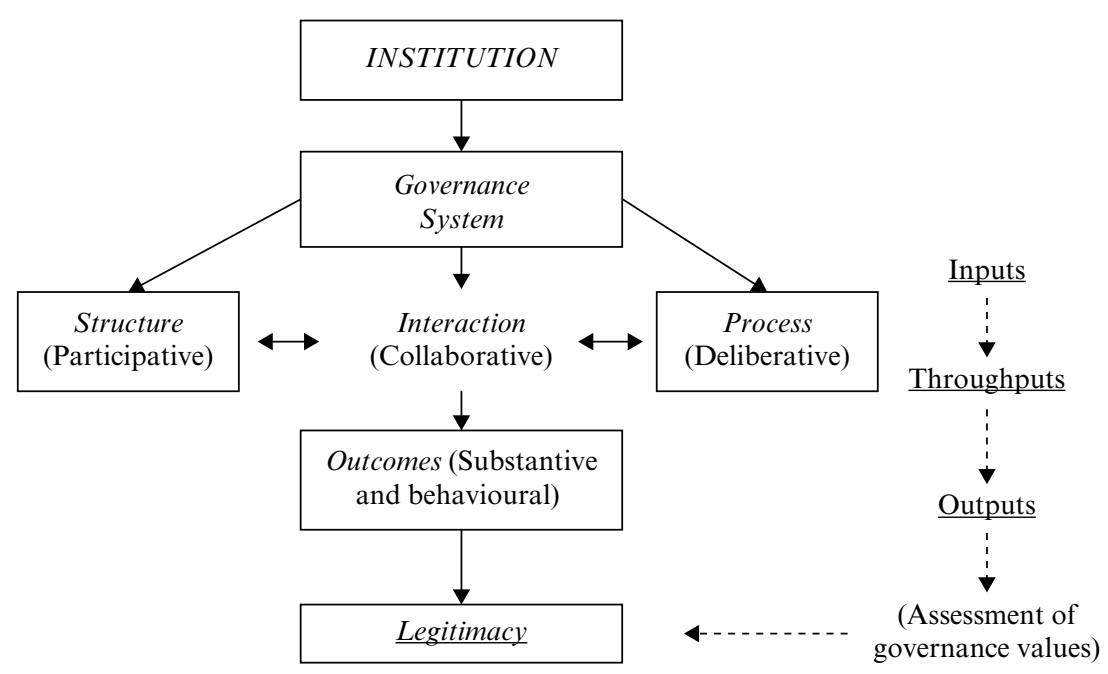

Source: Cadman (2011, p. 5, adapted; courtesy of Palgrave Macmillan).

Figure I.1 Analytical model for the evaluation of governance legitimacy 


\section{APPROACH AND METHODS OF EVALUATION}

\section{Ecological Modernization and the Case Studies}

In the period between the 2010 Cancun COP and the 2015 Paris COP there was increasing concern among observers and interest groups that the climate agreements may not deliver their target of containing the increase in global temperatures. Civil society was becoming disenfranchised, negotiators could not agree measures to address the ambition gap, there were claims for compensation from developing countries and disputes over intellectual property rights (for example, Climate Action Network, 2012; Fisher, 2010; Eastwood, 2011). These events lead to the question as to whether an operationalized theoretical framework such as EM can guide the policy development process and policy choices towards effective climate change policy.

The negotiation of the international agreements is a complex and lengthy process that demonstrates the commitment of the states to the environment and, in particular, to addressing climate change; a commitment that it is expected will guide their approach to domestic policy development. The agreements are not framed by a theoretical model and an operationalized EM may best serve the states in the adaptation of the international and domestic policy development processes as states adapt to the economic and social changes necessary to reduce their GHG emissions. Each nation-state has unique political and cultural sensitivities that influence policy choices, which may also be a constraining factor over the implementation of other versions of EM.

To establish if significant gaps exist between the EM framework with the UNFCCC agreements and domestic climate change policy, a test was conducted in a sample of countries to inform investigation into how EM can be operationalized and to determine its relevance as a guide in the policy development process. This book overlays an EM template intended to identify differences between the elements that make up EM and the climate change policies of the chosen sample of climate agreements and signatories (UNFCCC itself, EU, UK, China and India) thereby highlighting if and where their policies diverge from the EM model (Chapter 2). The test found there were differences, for example, whereas an ideal objective of EM is the decoupling of economic development and environmental protection, the UNFCCC seeks to achieve the multiple objectives of containing global warming, promoting economic growth and social development; the European Union and UK have added energy security as an imperative, and in India and China, the institutions of the state, market and civil society are weak. Until the 2015 Paris COP, the UNFCCC agreements 
also exempted some of the world's major GHG emitters (China, India, Brazil and Indonesia) from legally binding commitments to reduce GHG emissions through the common but differentiated responsibilities (CBDR) provisions. While preliminary, the test suggests that the expectations of the contribution of the theoretical framework can only be to that common aspect of the defined objectives.

In essence, the theoretical framework helps evaluate the performance of climate policy using a set of measurable conditions. To that end and, as established in the experiment, an operationalized EM would serve to identify where there are gaps in the suite of policies and programmes that may inhibit the ability to achieve the targeted ecological outcome, recognizing there may be other factors that could also create such a barrier but are outside the scope of the theoretical framework.

The UNFCCC's Kyoto Protocol (UNFCCC, 1997) and the INDCs under the 2015 Paris Agreement provide for ratifying nations to commit to specific targets and timeframes concerning emission reductions and many member states, particularly in developed economies, have framed domestic policies with these targets as outcomes. An examination of the INDCs of the countries profiled in this study provides an opportunity to explore the ability to guide the policy development process in pursuit of the emission reduction target. In Table I.1 a qualitative scoring has been attached to the case studies, based on the relationship between the INDCs and the EM framework. The identified assessment parameters of the EM framework presented in this book are innovation and technology, the market, interventions of the state, the role of civil society, and ecological consciousness (see Chapter 2). While EM theorists generally speak of EM on a scale of weak to strong, it was considered that policymakers would be better assisted by a more definitive measure. To that end and with consideration of the Pathways to operationalize EM as discussed in Chapter 2 measures of low, medium and high were adopted in place of the weak to strong scale, and the values of 0,5 , and 10 were applied to low, medium and high (weak to strong) models of EM. The results are reflected in Table I.1.

In Table I.1, overlaying the EM template permits a focus on the core issues necessary to the achievement of the desired outcomes and identifies those extraneous issues that can be used to evaluate policy priorities and choices. The table demonstrates, for example, that for Kenya and India, policies are conditional on international technical and financial support, and in the case of India, institutions of the state are weak and the capacity to support the strategies is limited. Australia has not aggressively tackled the problem and Canada has a varied history. With the discovery of coal tar sands, Canada withdrew from the Kyoto Protocol, although the 


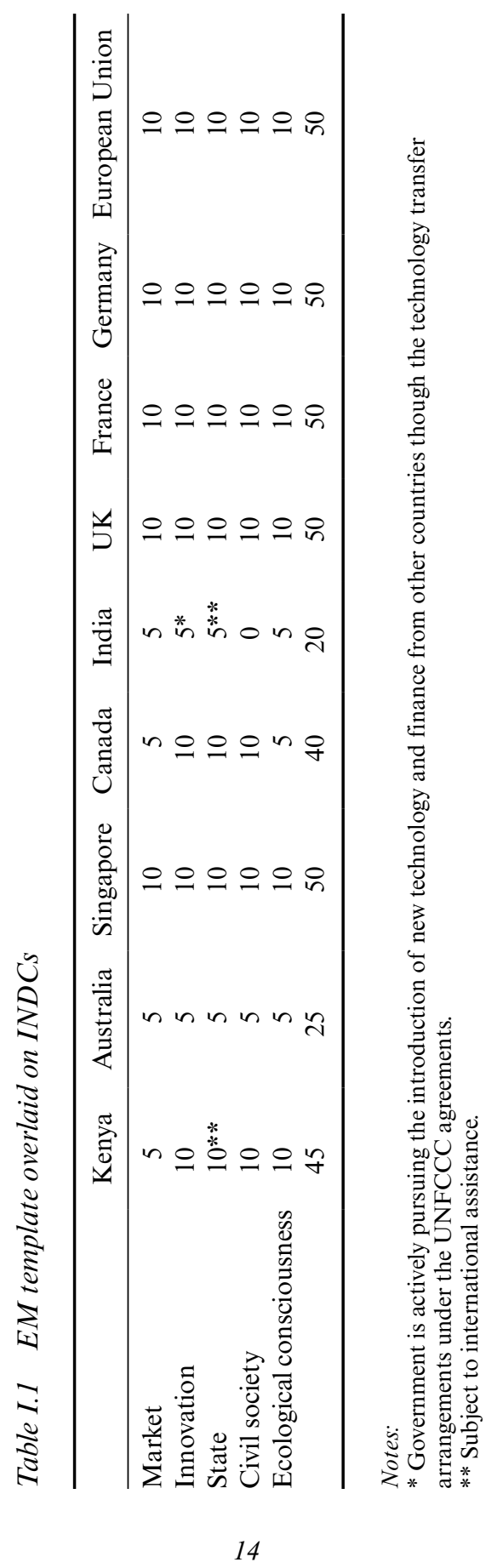

Peter J. Glynn, Timothy Cadman, and Tek N. Maraseni - 9781786430120 
country's recent change from a Conservative to Liberal government sees it revert to support for the international process.

Overall, the investigations conducted in this book find that while climate-related agreements and policies examined can be described as demonstrating elements of what some scholars refer to as 'strong' EM, multiple objectives introduce factors that mitigate against the successful application of the EM framework - and consequently the optimum policy choices to deliver the ecological outcomes desired. Chapter 1 explores these issues in more detail, presenting a new approach to evaluating policy effectiveness against EM theory, which moves away from previous notions of 'weak' or 'strong', and suggests a more nuanced approach instead.

\section{Stakeholder Perspectives on the Quality and Legitimacy of Climate Governance}

In addition to the application of EM theory to the case studies selected, the book also presents the results of a survey aimed at determining and evaluating the perspectives of civil society (such as employers' organizations and trade unions) on the governance arrangements for climate change policymaking at the intergovernmental, regional (EU), national, local and other levels. Specifically, survey participants were asked to rate their perspectives on how meaningful they thought their participation was in climate policy and how productive they thought the related policy deliberations were. Having established the linkages between EM theory and governance legitimacy in the discussions above, it is important to stress that consistent methods of evaluation are also required to determine whether the governance of policymaking sufficiently expresses the collaborative arrangements required to combat climate change effectively. Table I.2 contains a comprehensive set of governance values using a hierarchical framework of principles, criteria and indicators (PC\&I), derived from a review of contemporary governance literature (Cadman, 2011).

PC\&I represent a means for assessment of sustainability, including climate change, and were popularized as a consequence of the 1992 Rio Earth Summit and reflected in its foundational document Agenda 21 (Rametsteiner et al., 2009). These sorts of framework arose to enable more consistent evaluation. This is achieved through the placement of each element in its appropriate location, from principles to criteria and from there to the appropriate indicator, to avoid overlap and duplication. A principle is an essential rule or value to be determined and is broken down into criteria, which for assessment purposes are further divided into indicators, also known as parameters, for measurement. Principles and criteria are ideational rather than directly measurable; hence assessment 
Table I.2 Hierarchical framework of governance values

\begin{tabular}{lll}
\hline Principle & Criterion & Indicator \\
\hline Meaningful participation & Organizational responsibility & Accountability \\
& & Transparency \\
& Interest representation & Inclusiveness \\
& & Resources \\
Productive deliberation & Decision-making & Equality \\
& & Democracy \\
& & Agreement \\
& Implementation & Dispute settlement \\
& & Behavioural change \\
& & Problem-solving \\
& & Durability \\
\hline
\end{tabular}

Source: Cadman (2011, p. 17, adapted). Reproduced courtesy of Palgrave Macmillan.

itself occurs at the level of the indicator (Lammerts van Beuren and Blom, 1997, pp. 5-35).

As a principle, meaningful participation relates to the governance structures in which stakeholders are involved. It is comprised of two criteria: interest representation and organizational responsibility. Three indicators make up interest representation: inclusiveness, which is concerned with who participates in the given institution (delegated representatives of state or non-state organizations); equality, which relates to the balance of power between different interests; and resources, which refers to the capacities (such as technical, institutional and/or financial) participants have to draw on in ensuring their interests are represented. Organizational responsibility consists of two related indicators: accountability, addressing the extent to which participants can be called to account by others within the system and the general public; and transparency, referring to the degree to which participants' actions are visible or open to scrutiny by others in the system and the public. The principle of productive deliberation is concerned with the processes of governance and is comprised of two criteria: decision-making and implementation. Decision-making contains three indicators: democracy, which applies to the arrangements in place for selecting preferences; agreement, pertaining to the manner in which preferences are selected (such as consensus or voting); and dispute settlement, which is concerned with the mechanisms for dealing with disagreements and/or conflict. Implementation includes three indicators: behavioural change, that is, whether the decisions made lead to modified conduct - in this case, in relation to altering practices that lead to danger- 
ous greenhouse gas (GHG) emissions; problem-solving, which concerns itself with the degree to which the initial predicament that led to institutional formation is successfully addressed - in this case in relation to the successful reduction of GHG emissions; and durability, encompassing the notions of adaptability, flexibility and longevity of the problem-solution. Such an approach makes a useful contribution to EM, as it allows for a comprehensive analysis of the institutional structures and processes underlying policymaking, which underpins the achievement of desired environmental outcomes.

\section{KEY FINDINGS AND CHAPTER OUTLINE}

\section{Key Findings}

The investigations in this book establish the effectiveness of public policy, and the role of stakeholders in structures and processes of climate changerelated policymaking. Preliminary indications are that domestic labour market planning is essential in responding to climate change, yet labour market and climate change policies are not linked. Second, although employers' organizations and trade unions are influential as climate change activists within civil society, they are not effective advocates when it comes to substantively influencing climate change policy or attracting attention to the labour market impacts of climate change. The investigations also highlight the importance of understanding the governance of climate change policy and its contribution to monitoring and evaluating the role of NSAs such as business and labour in policymaking.

The findings of the book are intended to provide guidance on the role and effectiveness of business and labour in climate change policy. In the debate about climate change and the public policy intervention, the need and benefit of labour market planning is often overlooked. Labour market planning needs to be included in climate change policy. Strategies to manage GHG emissions are uniquely local and reflect many influences, such as the domestic economic, social, cultural and political situation of a country. However, all of these strategies have an impact on the labour market in addition to the normal and customary turnover of labour. Adjustments to labour planning by the state and industry need consideration if the demands for labour by industry are to be met and so that workers will be treated fairly during the transition to and in a new low carbon economy.

The book also offers an opportunity to explore the role of civil society. While EM theorists' references to civil society often directly or indirectly 
imply environmental activists, the book concentrates more specifically on how ecological modernization theory embraces the activities of the employers' organizations and trade unions, but also looks in passing at other interest groups formally recognized by the UNFCCC as civil society. Research by advisory bodies such as Eurofound (2011a), CEDEFOP (2010), OECD (2013b) and ILO (2012) finds that social partners, employers' organizations and trade unions have an important role to play in the development of climate change policy and the transition to a low carbon economy. The book also finds that the institutional framework of the EU confers authority on the social partners even though they are not necessarily the most capable or most representative organizations. In practice, the contribution of the social partners in the member states to the process of developing climate change policy reflects different levels of commitment. Their work programme does not always prioritize climate change but rather reflects the current issues of the day.

The book also establishes that what is a priority issue in one state may bear no resemblance to the work programme in another state that has a different economic profile and where the history, culture and tradition has cultivated different relationships. The UK study in particular demonstrates how culture, history and tradition can frame the statutory influences, attitudes and priorities of an organization. For example, with labour relations, in which the UK government has traditionally adopted a non-interventionist approach, negotiations occur at the level of the workplace and collective bargaining is voluntary. This means that the members' expectations for service by the Confederation of British Industry (CBI) and the Trades Union Congress (TUC) are different from the service delivery expectations of employers' organizations and trade union members in other EU member states where the labour market and the role of the social partners is more regulated. The EU member states are also at different stages of economic and institutional development, therefore the contributions by the social partners and the outcomes of social dialogue across the member states will vary. This is true also for countries outside the EU, such as Kenya and India.

The results of the governance survey are interesting. Overall, none of the levels of climate-related policymaking performed especially well in terms of perceptions of governance quality among survey respondents. There was a general preference for policymaking at the national level, notably amongst EU respondents. Employers' associations which participated in the survey did not view policymaking as being particularly transparent or accountable, but they were generally satisfied with its inclusiveness and equality. Trade unions, on the other hand, did not have such issues with accountability and transparency but were more 
concerned about issues of inclusiveness and equality. All respondents indicated that the level of resources afforded to them by policymaking institutions was very low. Additionally, respondents also generally perceived the problem-solving capacity of climate policymaking to be weak. Here it may be possible to determine a sense of frustration amongst respondents with both the structures and the processes of climate policymaking. While they may be able to forge a seat for themselves at the negotiating table to a certain degree, what they can achieve once they are there is questionable.

In view of the fact that EM is now over thirty years old, this book consequently suggests some modifications to EM theory in the light of current developments. Here, an understanding of the constraints placed on ecological outcomes by policy processes themselves, as well as more detailed governance assessments, focusing on the role of civil society actors, would help clarify EM theory. The model to operationalize EM theory presented here suggests that different contexts generate different policy frameworks and outcomes. The model also suggest that the achievement of outcomes is dependent on the policy choices generated as a consequence of distinctive political, institutional and cultural features, the national economic importance of specific sectors and, for example, the extent of the environmental impact of particular industries.

The book also stresses the importance of creating and maintaining political interactions that are transparent and democratic and ensuring that social movements are included in policymaking (Howes et al., 2010; Christoff, 1996). Within this scenario, the role for social partners (such as employers' organizations and trade unions) is as civil society actors whose opportunities are enhanced in the 'stronger' versions of EM. If climate policymaking is to afford civil society those opportunities, greater attention must be given to enhancing the interest and representation of NSAs (including enhanced institutional and technical support) as well as demonstrating greater levels of accountability and transparency. Without these, the implementation capacity of policymaking will remain constrained due to power asymmetries between state and NSAs - and climate change will remain an intractable issue.

\section{Chapter Outline}

Having introduced the subject matter, case studies and the approaches and methods relevant to understanding the role of business and organized labour in climate change policy, Chapter 1 discusses the understanding of and approach to ecological modernization used in the book. It examines EM in its historical and current contexts, the variations in the 
interpretation of the components of EM, and their interactions. It further explores the operationalization of EM from a theoretical concept to a practical framework that can guide public policy, and presents a new approach for doing so. The chapter reflects on the potential for conflict between the competing priorities of EM's theoretical framework and the policy constraints arising from the imperative to satisfy multiple objectives. Chapter 2 looks at the labour market impacts of climate change and the role of employers' organizations, trade unions and civil society on policymaking in different countries and policymaking forums. Chapters 3-6 comprise the case studies that inform the research. Chapters 4 and 5 are related chapters that comprise profiles of countries active in the climate policymaking arena and evaluate their policy responses in the light of the EM framework presented in Chapter 1. Chapter 3 focuses on countries within the EU, while Chapter 4 investigates five countries that have the common thread of being former British colonies and so have similar legal systems, language and certain common cultural influences. Chapter 5 evaluates the EU as a region while Chapter 6 looks at the UK; these are studied in detail because they provide mature models of climate change management and effective participation in the negotiation of the governing treaties and can therefore provide interesting insights into both climate policymaking and EM theory. Chapter 7 comprises a comparative analysis of the country profiles and case studies. Chapter 8 consists of an evaluation of the perspectives of civil society (employers' organizations, trade unions and other actors) on the governance arrangements for climate change policymaking at the intergovernmental, regional, national, local and other levels. The concluding chapter comments on the analysis and findings of the book and presents some suggestions regarding what actions are needed to improve sectoral involvement in, and uptake of, climate-related policy for policymakers, business and labour.

\section{NOTE}

1. Further to the negotiations under the Ad Hoc Working Group on the Durban Platform for Enhanced Action (ADP), the Conference of the Parties (COP), by its decision 1/ CP.19, invited all Parties to initiate or intensify domestic preparations for their INDCs towards achieving the objective of the Convention as set out in its Article 2. Without prejudice to the legal nature of the contributions, in the context of adopting a protocol, another legal instrument or an agreed outcome with legal force under the Convention applicable to all Parties. In decision 1/CP.20 it is further specified that in order to facilitate clarity, transparency and understanding, the information to be provided by Parties communicating their intended nationally determined contributions may include, as appropriate, inter alia, quantifiable information on the reference point (including, as appropriate, a base year), timeframes and/or periods for implementation, scope and 
coverage, planning processes, assumptions and methodological approaches including those for estimating and accounting for anthropogenic greenhouse gas emissions and, as appropriate, removals, and how the Party considers that its intended nationally determined contribution is fair and ambitious, in light of its national circumstances, and how it contributes towards achieving the objective of the Convention as set out in its Article 2 (UNFCCC, 2015). 